\title{
Cauda equina syndrome complicating ankylosing spondylitis: use of electromyography and computerised tomography in diagnosis
}

\author{
ADAM YOUNG, ADRIAN DIXON,* JOHN GETTY, PETER RENTON, \\ AND HENRI VACHER
}

From the Departments of Rheumatology, Orthopaedic Surgery, and Radiology, Royal National Orthopaedic Hospital, 234 Great Portland Street, London WIN 6AD, and the *Department Radiology, St Bartholomew's Hospital, West Smithfield, London EC1

SUMmARY A case of the cauda equina syndrome complicating ankylosing spondylitis (AS) is described. An unusual feature of this case was the relapsing and remitting nature of the condition, but there is sufficient evidence to explain the clinical picture on the basis of a recurrent intraspinal inflammatory process. The clinical and radiological features are similar to those of a further 28 reported in the literature. An electromyogram (EMG) proved important in defining the extent of neurological involvement. Computerised tomography (CT) showed marked laminar erosion and no bony exit foramen encroachment. We believe that the clinical diagnosis of this condition can be adequately confirmed with plain radiology, EMG, and CT scan.

Von Bechterew ${ }^{1}$ first described the neurological abnormalities seen in ankylosing spondylitis. Although his clinical descriptions are incomplete, he demonstrated degeneration of the posterior nerve roots of the lumbosacral nerves and dorsal columns and considered the possibility that the disease primarily affected spinal epidural tissue. Nearly 70 years later 2 further papers ${ }^{2} 3$ independently established a definite association between the cauda equina syndrome and ankylosing spondylitis (AS). A total of 28 cases have now been reported in the world literature. The characteristic clinical picture is usually confirmed with typical myelographic appearances. ${ }^{4}$ Various unsuccessful forms of therapy have been described, including steroids ${ }^{5} 6$ and decompression laminectomy. ${ }^{278}$ We report the relative value of computerised tomography (CT) the electromyogram (EMG), and plain and contrast radiology for investigating and establishing the diagnosis of this condition, the aetiology of which is still unknown. Some observations on the pathogenesis of this syndrome are made from previous

Accepted for publication 8 August 1980

Correspondence to Dr A. Young, Department of Rheumatology, Arthur Stanley House, Tottenham Street, London W1P9PG. reports and from our records of this patient's clinical progress, investigations, and response to a nonsteroidal anti-inflammatory drug (NSAID).

\section{Case report}

The patient, a 68-year-old retired man, first presented to this department with severe back and leg pain in 1977. He had first developed low backache and bilateral hip pain when he was 14 years old. A diagnosis of tuberculous hips was made when he was 20 years old and treatment was with bed rest and plaster immobilisation. A diagnosis of AS was eventually made when he was 26 years old, and he was treated with radiotherapy. He subsequently had unsuccessful arthroplasties of both hips and further courses of radiotherapy. His musculoskeletal symptoms then remitted for 30 years. A retropubic prostatectomy was performed for benign prostatic hypertrophy in 1970, and he has had regular cystoscopies since 1975 for benign papillomata. He developed recurrent attacks of iritis in 1976. In 1977 he presented with low backache and pain in his right leg and instep, at which time he was found to have absent ankle jerks and sensory impairment of 
the first sacral dermatome of the right leg in the presence of complete ankylosis of the hips and thoracolumbar spine. Symptoms settled after 4 months with the help of indomethacin $(125 \mathrm{mg} /$ day $)$ and dihydrocodeine tartrate (DF118, $150 \mathrm{mg} /$ day), though they did not completely remit. A year later he noticed gradually increasing pain in his right leg and foot, worse on recumbency, and associated with sensory symptoms. He also had similar but milder symptoms on the left side. In addition he had noticed constipation and a different type of low back pain which radiated into both buttocks and which was relieved by bed rest. He had always been a stoical patient, but he now felt he was unable to live with this severe and persistent pain. Clinical assessment of lumbosacral nerve root involvement was made difficult because of complete ankylosis of the hips, fixed flexion deformities of both knees, and ankle deformities. However, the findings of sensory impairment of the S2, 3, and 4 dermatomes on the right and of the S1 and 2 dermatomes on the left were consistent with a cauda equina lesion.

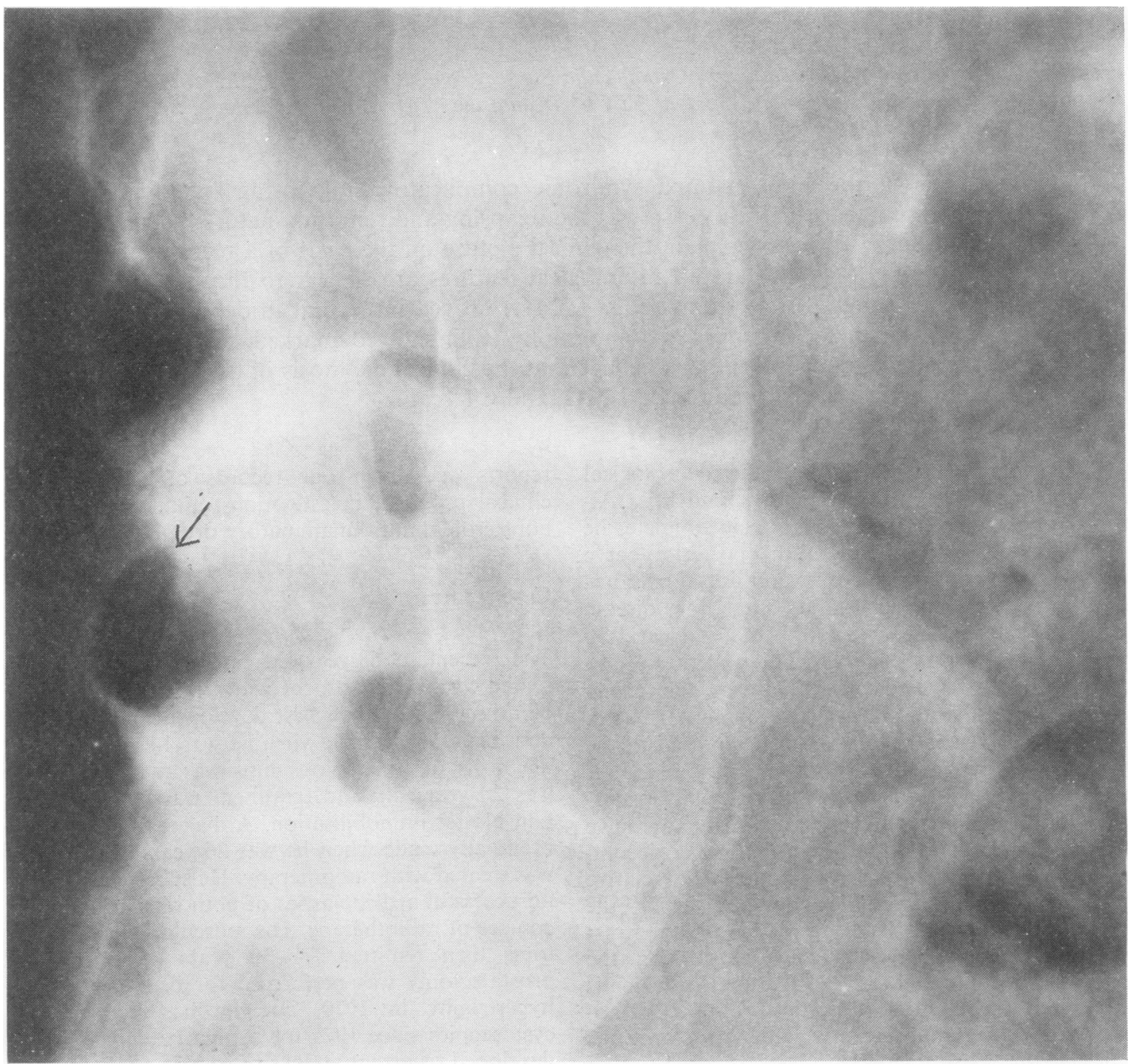

Fig. 1 Lateral lumbar spine. The plain film shows classical changes of ankylosing spondylitis with squaring of the vertebral bodies and paraspinal ossification. Apophyseal joints are fused. In addition, well-demarcated erosions (arrowed) are seen at the laminae and bases of the spinous processes. The sagittal diameter of the spinal canal is markedly increased. 


\section{INVESTIGATIONS}

Plain $x$-rays of the lumbosacral spine showed the typical 'bamboo spine' of AS and also multipleerosions of the roof of an enlarged spinal canal (Fig. 1).

EMG revealed partial denervation of the muscles normally supplied by the L3, 4 , and 5 and $S 1$ nerve roots bilaterally. Fibrillation potentials were also found in the paraspinal muscles supplied by the posterior primary rami of the lumbar nerves, suggesting a proximal lesion. Sensory action potentials of both sural nerves were delayed and reduced outside the normal range, but there was no evidence of a generalised peripheral neuropathy.
A metrizamide radiculogram displayed a wide canal and, from the level of L2 down, numerous large arachnoid diverticula filling the excavations of the laminae and of the bases of spinous processes seen on plain $x$-ray (Fig. 2). This procedure caused an acute severe relapse of his symptoms.

A CT scan showed the spinal canal enlarged by laminar erosions. No bony encroachment of the exit foramina was demonstrated (Fig. 3).

\section{MANAGEMENT}

He was treated with bed rest, DF118, 90 to 150 $\mathrm{mg} / \mathrm{day}$, and indomethacin $25 \mathrm{mg}$ t.d.s. and $50 \mathrm{mg}$

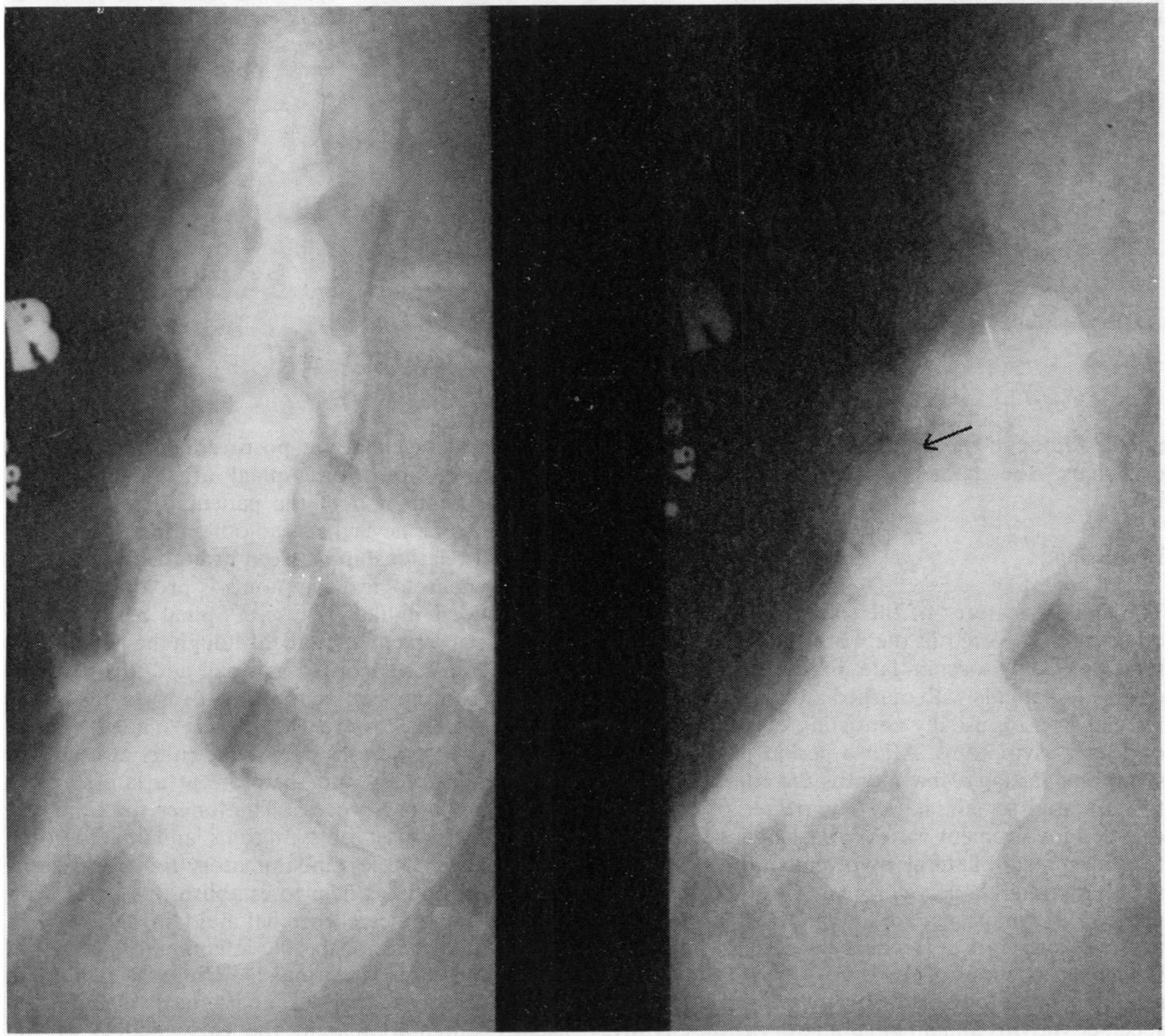

Fig. 2 Radiculogram. Puncture of the spinal canal of this patient was remarkably easy despite ankylosis because of the width of the spinal canal. Numerous saccular diverticula situated dorsolaterally fill with contrast, especially when the patient is erect. The diverticula (arrowed) fit exactly into the erosive defects on the plain film. 


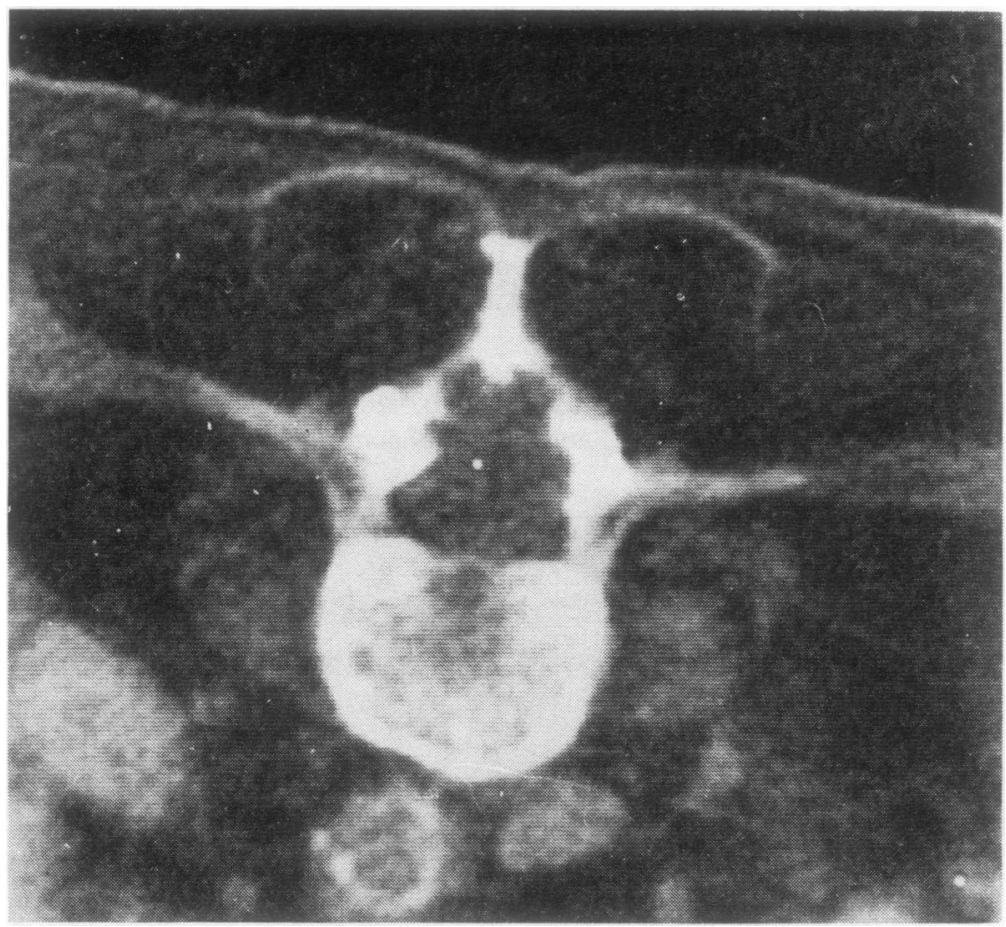

Fig. 3 Computerised tomogram at the level of the pedicles of L3. Note the spinal canal markedly enlarged posteriorly with thin eroded laminae. Discrete apophyseal joint spaces could not be identified. There is substantial atrophy of the muscles surrounding the vertebral column.

nocte. Although there was no change in his physical signs, the pain subsided to an acceptable level.

\section{Discussion}

The clinical features of this case are similar to the other cases reported in the world literature. ${ }^{9-12}$ The syndrome only occurs late in the course of the disease in patients with marked ankylosis and has an insidious onset, usually consisting of radicular pain or sensory symptoms. After a period of progressive symptoms lasting a few months the condition tends to settle and remain static. The degree of clinically detected involvement varies from 1 or 2 sacral roots to widespread bilateral involvement of nearly all the lumbosacral nerve roots. Constipation and urogenital symptoms are common, and previous prostatic surgery is a frequent finding.

The pathogenesis of AS is unknown, ${ }^{13}$ though the articular pathology appears to comprise a nonspecific synovitis and an inflammatory enthesopathy, a term used by Ball14 to describe the abnormality of ligamentous attachment to bone characteristic of the disease. Several mechanisms have been suggested to explain the damage to the lumbosacral nerve roots, ${ }^{4}$ including demyelination, postirradiation ischaemia, and compression from spinal arachnoiditis. The fact that about half of the patients described with this syndrome never had radiotherapy and that the temporal relationship between radiotherapy and the onset of neurological symptoms is prolonged, make radiation an unlikely cause..$^{15}$ Spinal arachnoiditis has been observed, ${ }^{2} 78$ and, although the nerve roots were then often recorded as small and atrophic, no obvious compression at the time of these investigations was seen. However, Matthews ${ }^{16}$ made the point that these observations were made either at necropsy or at laminectomy and therefore at a late stage in the inflammatory process. The longer the time gap between the onset of symptoms and macroscopic observations, the less inflammatory tissue was seen. Two other findings help to establish this point. The examination of cerebrospinal fluid in early AS is consistent with a nonspecific inflammatory response but in late cases is normal. ${ }^{817}$ Contrast radiology, which demonstrates the anatomical changes, is usually unremarkable in the early course of the condition.

None the less, arachnoiditis is known to be associated with degeneration of nerve roots, and, although direct proof is missing, ischaemia is 
thought to be a likely cause. The posterior root ganglia and nerve roots are highly vascular structures and very susceptible to ischaemia, especially in the lateral recesses and root canals. ${ }^{18}$ Involvement of the posterior root ganglia or postganglionic nerve root was likely in our case because of reduced sural nerve sensory action potentials found at EMG.

Milde et al. ${ }^{6}$ reported that in 1 of their 3 cases the nerve roots were impinged upon by the arachnoid diverticula. Although this is an uncommon finding, the formation of these diverticula has been frequently described and produces the plain radiological feature so characteristic of the condition (Fig. 1). Matthews ${ }^{16}$ explains this by postulating that the inflammatory response results in arachnoid adhesions, which form blind pouches into which cerebrospinal fluid (CSF) is forced by the pumping expansion of arterial pulsation. It has been suggested that raised intraspinal pressure may damage the spinal nerves as well as produce the bony erosions seen radiologically and at necropsy.

Whatever the mechanism, at some stage the nerve roots are damaged and many reports suggest that this occurs as a late result of the mechanical effects of previous inflammation. Certain features in our patient, however, favour the view that the nerve root damage occurs at the time of acute inflammation.

The case report of this patient shows that over a 3-year period he quite clearly had 2 'attacks' of this complication of AS. Both episodes manifested mainly as severe pain and both resolved partially with the help of a NSAID. Each episode was associated with low backache and a raised ESR. This has not been previously reported in those patients with sufficient follow-up, and would tend to support the concept of a recurrent intraspinal inflammatory process causing damage to the spinal roots either by direct pressure or as part of a vasculitis. Although the episodes of iritis did not coincide with the neurological symptoms in this patient, the former also represent episodes of inflammatory activity in tissues still susceptible to involvement by the immunopathological process as opposed to the 'burnt out' axial skeleton. There is evidence of more widespread inflammatory changes occurring in AS apart from the well known pulmonary and cardiac involvement, namely, in paraspinal muscles, ${ }^{19}$ gastrointestinal tract, ${ }^{20}$ presacral and paravertebral lymph nodes, ${ }^{21}$ and occasionally generalised severe constitutional disturbances such as fever. ${ }^{22}$ We would modify Von Bechterew's early observation and suggest that the peridural tissue can be a target organ for what is generally believed to be a genetically mediated immune response. ${ }^{23}$ It is clearly desirable to treat this condition positively during its active stage. Intrathecal steroids have been proposed, ${ }^{6}$ but radiotherapy may be more effective. It would be important therefore to recognise this complication at an early stage. This is often difficult because of initially minor symptoms and clinical signs in the presence of a chronic musculoskeletal disorder.

We would like to draw attention to the important diagnostic aid of the CT scan and EMG in the assessment of this patient. Although the latter involves an invasive technique it is virtually free of complications. The full extent of neurological involvement was difficult to determine because of joint deformities, but an EMG revealed widespread spinal disease. The metrizamide radiculogram merely served to confirm what was, in retrospect, obvious on the plain film, namely, erosions of the roof of a widened canal. This radiological feature was recognised in about half of the case reports of this condition described in the world literature. Local cord stenosis following arachnoiditis would be unusual in the presence of large chronic diverticula and a widened canal. The original purpose of the radiculogram was to rule out a local compressive lesion, though electrical evidence made this unlikely. It caused, in this patient, a considerable flare-up of his symptoms, presumably as a result of arachnoiditis. We feel, therefore, that radiculography, though informative and dramatically illustrative of the gross anatomical changes in this condition, is not necessary in the absence of clinical and EMG evidence of localised pathology. It may even be harmful to the patient, especially if those contrast media known to cause arachnoiditis are used.

CT scanning is not generally available in the United Kingdom but does have the advantage of being noninvasive. Although it was performed relatively late in the development of this condition, it showed the characteristic laminar erosions and the absence of foraminal encroachment of nerve roots. These findings are similar to the one other report described in this connection. ${ }^{24}$ If performed in early cases, the CT scan may prove useful in unravelling the pathogenesis of the condition, especially the bony erosions. The early onset of the cauda equina syndrome may be more easily diagnosed with electrical methods, particularly in patients with insidious symptomatology and equivocal or absent clinical signs, or in whom the presence of deformities makes clinical assessment difficult.

We thank Dr Mary Corbett and Dr Michael Sullivan for allowing us to report on their patient and $\mathrm{Dr} \mathrm{R}$. Ebringer for help and advice in preparation of this report.

We are grateful to the trustees of St Bartholomew's Hospital for their generosity in providing the CT scanner and supporting one of us (A.K.D.). 


\section{References}

1 Von Bechterew W. Streifigheit der Wirbelsaule und ihre Verkummung als besondere Erkrankensform. Neurologisches Centralblatt 1893; 12: 426-34.

2 Hauge T. Chronic rheumatoid polyarthritis and spondylarthritis associated with neurological symptoms and signs occasionally simulating an intraspinal expansive process. Acta Chir Scand 1961; 20: 395-401.

3 Bowie E A, Glasgow E L. Cauda equina lesions associated with ankylosing spondylitis. Report of 3 cases. $\mathrm{Br}$ Med J 1961; ii: 24-7.

4 Thomas D J, Kendall M S, Whitfield A G W. Nervous system involvement in ankylosing spondylitis. $\mathrm{Br} \mathrm{Med} J$ 1974; 1: 148-50.

5 Russell M L, Gordon D A, Ogryzlo M A, McPhedron R S. The cauda equina syndrome of ankylosing spondylitis. Ann Intern Med 1973; 78 : 551-4.

- Milde E-J, Aarli J, Larsen J L. Cauda equina lesion in ankylosing spondylitis. Scand $J$ Rheumatol 1977; 6: 118-22.

7 Lee M L, Waters D J. Neurological complications of ankylosing spondylitis. $\mathrm{Br}$ Med J 1962; i: 798.

8 Gordon A L, Yudell A. Cauda equina lesion associated with rheumatoid spondylitis. Ann Intern Med 1973; 78: 555-7.

- Goldenberg G J, Logothetis J. Neurological manifestations in 2 cases of ankylosing spondylitis. Lancet 1961 ; i: 448-50.

10 McGill I G. An unusual neurological symptom associated with ankylosing spondylitis. Guy's Hosp Rep 1966; 115: 33-6.

11 Rosenkranz W. Ankylosing spondylitis: Cauda equina syndrome with multiple spinal arachnoid cysts. Case report. J Neurosurg 1977; 34: 241-3.
12 Hassan I. Cauda equina syndrome in ankylosing spondylitis: a report of six cases. J Neurol Neurosurg Psychiatry 1976; 39: 1172-8.

13 Cruickshank B. The pathology of ankylosing spondylitis. Clin Orthop 1971; 74: 43-58.

14 Ball S. Enthesopathy of rheumatoid and ankylosing spondylitis. Ann Rheum Dis 1971; 30: 213-23.

15 Zeman W, Samorajski T. Effects of irradiation on the nervous system. In: Berdjis C C, ed. Pathology of Irradiation. Baltimore: Williams and Wilkins, 1970.

16 Matthews W B. Neurological complications of ankylosing spondylitis. Neurol Sci 1968; 6: 561-73.

17 Boland E W, Headley N E, Hench D S. The C.S.F. in rheumatoid spondylitis. Ann Rheum Dis 1948; 7 : 195-9.

18 Domisse G F. Failures of laminectomies for disc protrusion.J Bone Joint Surg 1977; 59B: 123.

19 Berman L, Isaacs H, Pickering A. Structural abnormalities of muscle tissue in ankylosing spondylitis. $S$ Afr Med J 1976; 50: $1238-40$.

20 Jayson M I V, Salwen P R, Harrison W J. Inflammatory bowel disease in ankylosing spondylitis. Gut 1970; 2 506-11.

21 Fournier A M, Denizet D, Delagrange A. La lymphographie dans la spondylarthrite ankylosante. $J$ Radiol Electrol Med Nucl 1969; 50: 773-84.

22 Kinsella P, Ebringer R, Hooker J, Corbett M, Cox N, Wynn Parry C B. Ankylosing spondylitis presenting as PUO. Br Med J 1978; ii: 19-20.

${ }^{23}$ Ebringer R. Spondylarthritis and post infections syndromes. Rheumatol Rehabil 1979; 18: 218-26.

24 Kramer L D, Krouth G S. Computerized tomography. An adjunct to early diagnosis in the cauda equina syndrome in ankylosing spondylitis. Arch Neurol 1978; 116-8. 